\title{
Liberalización de servicios públicos locales y modalidades de actuación local en los sectores liberalizados
}

\section{Liberalization of local public services and modalities of local action in the liberalized sectors}

\author{
Joaquín Tornos Mas \\ Universidad de Barcelona \\ jtornos@tornosabogados.com
}

\begin{abstract}
RESUMEN
En los últimos años hemos asistido a un proceso de creciente liberalización de servicios públicos, lo que supone devolver al mercado actividades económicas que se habían excluido del mismo. Este proceso ha sido menor en el ámbito local, pero también han existido casos de liberalización de servicios públicos locales, como es el caso de los servicios funerarios. Este trabajo examina estos procesos de liberalización y sus consecuencias, analizando qué competencias pueden ejercer los municipios en relación a los servicios liberalizados, que no obstante su devolución al mercado siguen siendo servicios de interés general.
\end{abstract}

\section{PALABRAS CLAVE}

Iniciativa pública económica, liberalización, obligaciones de servicio público, servicio público, servicios funerarios.

\begin{abstract}
In recent years we have witnessed a process of increasing liberalization of public services, which means returning economic activities that had been excluded from the market. This process has been less at the local level, but there have also been cases of liberalization of local public services, such as funeral services. This paper examines these liberalization processes and their consequences, analyzing what powers municipalities can exercise in relation to liberalized services, which, despite their return to the market, remain services of general interest.
\end{abstract}

\section{KEYWORDS}

Public economic initiative, Liberalization, public service obligations, public service, funeral services.

\section{SUMARIO}

I. LA LIBERALIZACIÓN DE SERVICIOS PÚBLICOS LOCALES. A) EL SERVICIO PÚBLICO LOCAL. B) LA LIBERALIZACIÓN DE LOS SERVICIOS FUNERARIOS Y LOS MERCADOS MUNICIPALES. II. MODALIDADES DE ACTUACIÓN EN LOS SECTORES LIBERALIZADOS. A) COMPETENCIAS DEL ENTE LOCAL SOBRE EL SERVICIO LIBERALIZADO. LA PRESTACIÓN DEL SERVICIO POR LOS PARTICULARES EN RÉGIMEN DE CONCURRENCIA. 1. Las competencias de ordenación en el caso de los servicios funerarios. 2. Servicio esencial y obligaciones de servicio público. 3. Las competencias de ordenación en el caso de los mercados municipales. B) ¿ES POSIBLE REMUNICIPALIZAR EL SERVICIO? C) ¿ES POSIBLE EL EJERCICIO DE LA INICIATIVA ECONÓMICA PÚBLICA EN LOS SECTORES LIBERALIZADOS? 


\section{LA LIBERALIZACIÓN DE SERVICIOS PÚBLICOS LOCALES}

\section{A) El servicio público local}

En los últimos años hemos asistido a un proceso creciente de liberalización de servicios públicos, lo que ha supuesto abrir el mercado a la prestación de actividades económicas que habían sido excluidas total o parcialmente del mismo por razones de interés general. El derecho comunitario ha impuesto de forma especial este proceso en relación a los llamados servicios públicos económicos, en general servicios prestados en red ( telecomunicaciones, gas, electricidad, transportes, servicios postales...).

Este fenómeno no ha sido tan intenso en el ámbito local, pero también se ha producido un cierto proceso de liberalización, de modo que los servicios públicos locales se han reducido.

La referencia a este proceso nos obliga a fijar en primer lugar qué entendemos por servicio público y por el proceso de su liberalización. Creemos que el concepto jurídico de servicio público debe identificarse con su acepción subjetiva. Por tanto, servicio público es aquella actividad cuya titularidad ha sido reservada en virtud de una ley a la administración para que ésta lo reglamente, dirija y gestione, en forma directa o indirecta, y a través de la cual se presta un servicio al público de manera regular y continua1.

Si llevamos este concepto de servicio público al ámbito local debemos precisar su relación con lo dispuesto en el artículo 25 de la Ley de Bases de Régimen Local. El citado precepto establece que «el municipio para la gestión de sus intereses y en el ámbito de sus competencias, puede promover actividades y prestar los servicios públicos que contribuyan a satisfacer las necesidades y aspiraciones de la comunidad vecinal en los términos previstos en este artículo». Y en sentido parecido, debemos analizar la relación con el artículo 85,1 de la misma LBRL, según el cual «son servicios públicos locales los que prestan las entidades locales en el ámbito de sus competencias» ${ }^{2}$.

Pues bien, a nuestro entender en el ámbito local únicamente se puede hablar con propiedad de servicio público respecto de aquellas actividades económicas que han sido objeto de reserva o publicatio. En este sentido se ha dicho que «el servicio público ha quedado referido mayoritariamente, al menos en la doctrina española, al conjunto de actividades prestacionales asumidas o reservadas al Estado con el fin de satisfacer necesidades colectivas de interés general, siendo por tanto la nota distintiva la publicatio, es decir, la titularidad pública de la actividad en cuestión y la subsiguiente quiebra de la libertad de empresa. Una publicatio que en ocasiones se acompaña de la gestión directa por la propia administración ( produciéndose así el monopolio de gestión $)^{3} »$. La reserva se lleva a cabo por razón de la vinculación de la actividad prestacional con el interés general, lo que justifica su exclusión del mercado y la correlativa asunción de la responsabilidad de su prestación por la administración local ${ }^{4}$.

Una decisión posterior es la que supone la «municipalización» del servicio, momento en el cual el ente local decide la asunción efectiva de la prestación, lo que supone dar efectividad a la reserva y excluir a la iniciativa económica privada. Por tanto, puede existir un servicio público local en virtud de su reserva legal a favor del ente local, pero éste puede no haber asumido su prestación efectiva al no haber llevado a cabo la municipalización ${ }^{5}$.

1 Sobre este concepto, vid. recientemente nuestro trabajo, TORNOS MAS, J., "El concepto de servicio público a la luz del derecho comunitario", RAP, núm. 200, mayo-agosto 2016, págs. 193 a 211.

2 Como se ha dicho recientemente «los municipios pueden ocupar fundamentalmente dos posiciones sobre sus servicios. Una es la posición que asumen por disponer de la competencia que les viene atribuida sobre diversos servicios y otra la posición que pueden alcanzar para ostentar la titularidad de los servicios públicos locales». ESTEVE PARDO, J., "Perspectivas y cauces procedimentales de la remunicipalización de servicios", RAP, 202, 2017, pág. 313.

3 La cita es de FERNÁNDEZ FARRERES, G. Sistema de Derecho Administrativo, 1. a edición, Civitas-Thomson-Reuters, Cizur Menor, Navarra, 2012, pág. 420. Vid. También TORNOS MAS, J., "La actividad de servicio público", en el libro colectivo coordinado por BANDRÉS y PAREJO, Las sentencias fundamentales del Tribunal Supremo en materia contencioso-administrativa, lustel, Madrid 2016, pág. 34 a 45.

${ }_{4}$ En este sentido, vid. DEL GUAYO CASTIELLA, I. Nuevo régimen jurídico de los servicios públicos locales, tras la Ley núm. 27/2013 de 27 de diciembre, de racionalización y sostenibilidad de la Administración local, REALA, núm. 2, julio-diciembre 2014. Para este autor, «hay una identidad conceptual entre servicios públicos y servicios esenciales reservados... la reserva comporta tanto la publicatio de la actividad, su titularidad pública, como la libertad de la Administración para gestionar el servicio reservado como estime más conveniente para los intereses generales, directa o indirectamente, con monopolio o sin él; el reverso de esta tesis es que la actividad en que consiste el servicio esencial reservado queda extraída del ámbito de la libre iniciativa económica de los ciudadanos, como una suerte de excepción a la libertad de empresa en una economía de mercado; desde un punto de vista práctico, la única forma al alcance de los particulares para operar en el ámbito reservado es la obtención de una concesión administrativa u otro tipo de contrato de gestión de servicios públicos».

5 Así, por ejemplo, existen aún municipios en los que el servicio de suministro de agua a poblaciones se lleva a cabo en virtud de títulos concesionales demaniales por una empresa privada al no haberse llevado a cabo la municipalización del servicio. 
Así, podemos decir que la ley de bases de régimen local en sus artículos 26 y 86 lleva a cabo la publicatio de diversas actividades. Pero luego, cada ente local debe llevar a cabo la municipalización de este servicio, esto es, el acuerdo de que asume de forma efectiva la garantía de esta prestación excluyendo la libre iniciativa económica, sin perjuicio de que después decida que esta actividad de su titularidad se pueda prestar a través de una forma de gestión directa o indirecta ${ }^{6}$.

Pues bien, precisamente por el hecho de que la reserva comporta la exclusión de la iniciativa económica privada respecto de una determinada actividad de contenido económico, la reserva debe estar contenida en la ley, ya sea en la ley básica de régimen local o en una ley sectorial específica.

De conformidad con esta interpretación, en la actualidad son servicios públicos locales los que así han sido declarados en los artículos 26 y 86 de la LBRL7. Todas estas actividades materiales, en razón de lo establecido en la ley básica de régimen local, son servicios públicos de titularidad y responsabilidad municipal.

El régimen de los servicios públicos está determinado por la reserva o publicatio de la actividad. Esta reserva supone que la actividad económica se sitúa fuera del régimen general del mercado en razón del interés general vinculado a esta prestación. La necesidad de que la actividad ( por ejemplo, el suministro de agua a poblaciones) se asegure en condiciones de asequibilidad, continuidad y calidad justifica el régimen especial de servicio público, por tanto, la no concurrencia y la prestación de conformidad con las reglas de derecho público. Pero esta reserva no supone la total exclusión de la actividad privada. Por un lado la actividad prestacional puede abrirse al sector privado mediante las formas de gestión indirecta del servicio ( lo que da lugar a la concurrencia por el mercado). Por otro, pueden existir servicios públicos que se presten en concurrencia con el sector privado ( por ejemplo, los servicios de educación o sanidad).

Cuestión diversa es si los entes locales pueden crear nuevos servicios públicos a partir de la competencia que les atribuye el artículo 25 de la LBRL. Sin analizar a fondo esta cuestión nos limitaremos a señalar en este trabajo que a nuestro juicio los entes locales pueden crear nuevos servicios públicos, asumiendo por tanto la responsabilidad de su prestación y la sumisión de la misma a un régimen propio de derecho público fuera de las reglas de mercado, si se trata de servicios que se prestan en concurrencia. No es posible si se pretende establecer un régimen de monopolio absoluto, de modo que sólo pueda accederse a esta prestación, en su caso, a través de una concesión u otra forma de gestión indirecta del servicio. En este caso, al excluirse totalmente la actividad del mercado se requiere una norma legal habilitante.

Como un ejemplo de servicio público de creación local puede citarse el caso de los aparcamientos. Un ente local puede decidir crear el servicio público de aparcamientos públicos, lo que supone que su actividad no se prestará en ejercicio de la iniciativa pública en la economía, sino que se situará fuera de las reglas de concurrencia en un mismo mercado con los empresarios privados que lleven a cabo esta misma actividad. Pero en este caso el servicio público local no impone un monopolio absoluto de la actividad y, por tanto, no se exige reserva legal. El título competencial en materia de ordenación del tráfico puede justificar la creación de este servicio público que, como servicio público, coexistirá con los aparcamientos privados. En este sentido se manifestó el Tribunal Supremo en su sentencia de 6 de mayo de 1999, Recurso de Casación núm. 2298/1993, Ponente Sr. Lescure Martín. Para el Tribunal «el concepto restrictivo de servicio público sobre el que gira su argumentación, coincidente con la acepción especial de servicio público esencial, esto es, de sectores de actividad reservados en principio, con o sin monopolio, a la iniciativa y gestión de la entidad pública (véase art. 128.2 CE), no se compadece con el concepto legal del artículo 85.1 de la Ley 7/1985, de 2 de abril, Reguladora de las Bases del Régimen Local, según el cual "son servicios públicos locales cuantos tienden a la consecución de los fines señalados como de la competencia de las Entidades locales", siendo de destacar la clara conexión que mantiene el servicio de aparcamiento público con la competencia sobre "la ordenación del tráfico de vehículos y personas en las vías urbanas", que el artículo 25.2 b) de la misma Ley atribuye a los Municipios» ${ }^{8}$.

6 En este mismo sentido ORTEGA BERNARDO, J., op. cit., pág. 67. La autora expone las diversas tesis sobre el concepto de reserva o publicatio y concluye que «considero que esta tesis que defiende que para la efectiva materialización de la reserva se requiere, además de la declaración legal, la voluntad de la propia Corporación local encargada de implantar el servicio, es la que interpreta adecuadamente lo que establece a este respecto nuestro ordenamiento jurídico y resulta congruente con la realidad económica y social de los municipios españoles». Vid. también MENÉNDEZ GARCÍA, P., "Una interpretación renovada de la reserva de servicios esenciales en favor de las entidades locales", REDA, 89, págs. 183-212.

7 Ciertamente la redacción de la LBRL no es técnicamente muy precisa, al no incluir en la reserva del artículo 86 todos los servicios que el artículo 26 declara servicios de prestación obligatoria.

8 Vid. Sobre esta sentencia y el concepto objetivo de servicio público, TORNOS MAS, J., op. ult. cit., págs. 39 a 42. 


\section{B) La liberalización de los servicios funerarios y los mercados municipales}

Pues bien, en el ámbito local también se han producido algunas «liberalizaciones» de servicios públicos, de modo que actividades prestacionales de contenido económico han dejado de calificarse como servicios públicos locales y estas actividades económicas se han devuelto al mercado.

Un primer ejemplo lo tenemos en el caso de los servicios funerarios. Los servicios funerarios estaban contemplados en el artículo 86 de la LBRL como servicios reservados a favor de los entes locales, lo que suponía que estos servicios estaban configurados como servicios públicos lo que, como hemos dicho, comportaba la titularidad del servicio a favor de los entes locales y, por tanto, la exclusión de esta actividad del régimen de mercado. El servicio podía prestarse de forma directa por el ente local, o bien de forma indirecta por empresas privadas a través del título concesional articulado mediante el contrato de gestión de servicio público.

Esta situación se modifica mediante la aprobación del Real Decreto ley 7/1996 de 7 de junio, de Medidas urgentes de carácter fiscal y de fomento y liberalización de la actividad económica, que liberalizó la prestación de los servicios funerarios en sus artículos 23 y 24. La liberalización se llevó a cabo suprimiendo los servicios funerarios de los artículos 26,1 -c y 86,3 de la LBRL ${ }^{9}$.

Este cambio normativo tuvo su traducción en la regulación específica de esta actividad. Así la ley catalana 2/1997 de servicios funerarios pasó a definir estos servicios como «servicios esenciales de interés general», pero ya no como servicios públicos, y modificó el régimen de acceso a esta actividad para las empresas privadas, pues del régimen de concesión se pasó al de autorización no contingentada. La ley también determinó que se trata de servicios de titularidad local y que las Ordenanzas municipales podrían establecer los requisitos mínimos de personal, vehículos, féretros y otros medios indispensables para poder obtener la autorización ${ }^{10}$. También dispuso que las Ordenanzas podrían exigir el servicio de tanatorio, con un número de salas determinado, y la titularidad de un local en el término municipal ${ }^{11}$.

Debe señalarse en este punto que lo que se liberalizó fueron los servicios funerarios, no los cementerios. Como recordó la sentencia del TSJ de las Islas Baleares, sala de lo contencioso-administrativo, de 29 de octubre de 2010, «debe distinguirse entre lo que constituye por un lado el servicio público esencial de cementerio, que engloba la regulación, construcción, cuidado y mantenimiento de las dependencias e instalaciones destinadas a este fin, y de otro, el servicio funerario, incluyendo en ese concepto el traslado de cadáveres y todo el conjunto de posibles prestaciones en relación al fallecimiento de una persona, entierro e incineración de cadáveres» ${ }^{12}$. Los cementerios siguen siendo bienes demaniales, y su cuidado y explotación sigue siendo de titularidad local. La regulación, construcción, cuidado y mantenimiento de las dependencias e instalaciones destinadas al fin de cementerio sigue siendo un servicio público local, según el artículo 26,1-a de la LBRL ${ }^{13}$.

No obstante lo anterior, debe también recordarse que el Decreto 2263/1974 de 20 de julio, por el que se aprueba el Reglamento de Policía Sanitaria Mortuoria, sigue vigente, y que su artículo 42 establece que «En toda población de más de 10.000 habitantes deberá existir, por lo menos, una empresa funeraria priva-

9 Vid. al respecto PARICIO RALLO, E., "Los servicios funerarios en la nueva tipología de servicios municipales". Quaderns de dret local, QDL, núm. 33, octubre 2013, págs. 77 a 89.

10 El Ayuntamiento de Barcelona, por ejemplo, aprobó su Ordenanza de servicios funerarios el 24 de octubre de 1997. En dicha Ordenanza se estableció que: «Artículo 2. Naturaleza jurídica de los servicios. 1. Los servicios funerarios tendrán la condición de servicios esenciales de interés general, los cuales pueden ser prestados por el Ayuntamiento, por empresas públicas o por empresas privadas, en régimen de concurrencia en todos los casos.

2. La prestación de los servicios funerarios estará sometida a las medidas de control, de policía y de autorización establecidas en esta Ordenanza, por la Normativa de Policía Sanitaria Mortuoria y por los reglamentos y Ordenanzas que se puedan dictar al efecto».

11 Posteriormente el Decreto legislativo 3/2010 traspuso para Cataluña lo dispuesto en la Directiva 123/2006, y modificó en parte la ley 2/1997. Concretamente reconoció la eficacia de la autorización de transporte funerario obtenida en un municipio para poder actuar en todo el territorio de Cataluña, estableció que los requisitos que puedan exigir las Ordenanzas para poder obtener la autorización han de ser proporcionados y deben respetar en todo caso la libre competencia, y se suprime la exigencia necesaria de poseer un tanatorio con un número mínimo de salas y el disponer de un local propio en el municipio donde se pretende actuar.

12 En este mismo sentido, la ley catalana 2/1997 establece en su artículo 4,1 qué debe entenderse por servicios funerarios, al decir que estos servicios incluyen las siguientes funciones: «1. a) Informar y asesorar sobre el servicio. b) Suministrar el féretro, que debe tener las características que correspondan según el servicio de que se trate, y urnas cinerarias y de restos, en su caso. c) Realizar las prácticas higiénicas necesarias en el cadáver, colocarlo en el féretro y transportarlo desde el lugar de defunción hasta el domicilio mortuorio, si procede, y hasta el lugar de destino final mediante un vehículo de transporte funerario autorizado. d) Realizar la gestión de los trámites administrativos preceptivos para todo el proceso hasta el entierro o incineración, de conformidad con la normativa aplicable, y para la inscripción de la defunción en el Registro Civil. e) Realizar las prácticas sanitarias en el cadáver. f) Prestar los servicios de tanatorio, en condiciones físicas adecuadas para el velatorio».

13 El Real Decreto 1225/2006 liberalizó en su artículo 139 el transporte de cadáveres. 
da o municipal, que cuente y disponga de los medios siguientes: a) Personal idóneo suficiente, dotado con prendas exteriores protectoras. b) Vehículos para el traslado de cadáveres, acondicionados para cumplir esta función. c) Féretros y demás material fúnebre necesario. d) Medios precisos para la desinfección de vehículos, enseres, ropas y demás material».

Una segunda liberalización es la que se ha producido en relación a los mercados municipales. La ley 27/2013, LRSAL, suprimió la referencia a los mercados como servicios obligatorios para municipios de más de 5.000 habitantes, tal y como establecía con anterioridad el artículo 26,1-b de la LBRL. De este modo este servicio dejó de poderse conceptuar como servicio público, y esta actividad quedó abierta al mercado sin que pudiera prestarse de acuerdo con las reglas exorbitantes del derecho público ${ }^{14}$.

\section{MODALIDADES DE ACTUACIÓN EN LOS SECTORES LIBERALIZADOS}

La liberalización de los servicios públicos locales, en los términos en que hemos definido este proceso, tiene dos consecuencias fundamentales. Por un lado la actividad económica prestacional que era el objeto del servicio (los servicios funerarios, el mercado municipal) se devuelve al mercado, por lo que las empresas privadas pueden acceder a esta actividad en régimen de concurrencia e igualdad. De esta forma de la concurrencia por el mercado hemos pasado a la concurrencia en el mercado. Por otro lado, la administración deja de ser la responsable de la prestación, ya que se confía en que será el mercado el que pasará a garantizar la prestación. Pero ello no supone que la administración no deba estar presente en la regulación del sector liberalizado, ni que no pueda actuar en el mismo como un competidor más. A partir de esta afirmación genérica pasamos a formular tres grandes cuestiones ¿Qué competencias de ordenación mantiene la administración sobre los servicios liberalizados? ¿Puede el ente local remunicipalizar el servicio liberalizado, puede decidir volver a prestar este servicio cómo servicio público? ¿ Puede llevar a cabo la iniciativa púbica económica en una actividad liberalizada, en qué condiciones?

\section{A) Competencias del ente local sobre el servicio liberalizado. La prestación del servicio por los particulares en régimen de concurrencia.}

La liberalización de un servicio público no supone que la administración pierda todos sus títulos de intervención ni sus obligaciones en relación con la actividad prestacional liberalizada. Los entes municipales siguen teniendo competencia en materia de servicios funerarios y de mercados, y por ello mantienen su capacidad de intervenir en ejercicio de su poder de regulación. Esta intervención, además, es especialmente necesaria cuando se trata de servicios de interés general, como es el caso de los servicios funerarios.

\section{Las competencias de ordenación en el caso de los servicios funerarios}

Los servicios funerarios, en la medida que consisten en los servicios relativos al tratamiento de las personas fallecidas, su traslado y entierro o incineración, se consideran servicios esenciales ${ }^{15}$. Por tanto, estamos ante un servicio que al liberalizarse deja de ser servicio público, pero en tanto mantiene su naturaleza de servicio esencial por razón de la prestación que comporta, se convierte en servicio económico de interés general, SIEG en la terminología comunitaria. Esto supone que la administración deberá hacer frente a situaciones de posibles fallos del mercado, que deberá tratar de garantizar la concurrencia para que exista oferta suficiente, de calidad y a precios asequibles, y que podrá imponer obligaciones de servicio público, como la atención a las personas que no puedan hacer frente al coste de la prestación del servicio.

Los municipios, por tanto, han dejado de ser titulares del servicio, pero mantienen su competencia de regulación. No son ya los responsables directos de su prestación ( ahora es el mercado), pero si deben ordenar el ejercicio de esta actividad privada de interés general, sin desvirtuar la liberalización del sector ${ }^{16}$.

14 Sobre los mercados municipales vid. GONZÁLEZ BUSTOS, M. A., El servicio municipal de mercado de abastos tras la ley 27/2013 de 27 de diciembre de racionalización y sostenibilidad de la administración local, en el libro colectivo coordinado por FONT LLOVET-DÍEZ SÁNCHEZ, Los servicios públicos locales. Remunicipalización y nivel óptimo de gestión, lustel, Madrid 2017, págs. 189-204.

15 Así, por ejemplo, el artículo 54 de la ley del sector eléctrico 24/2013 de 26 de diciembre, al relacionar los servicios esenciales a los que no puede dejar de prestarse el servicio de suministro eléctrico, incluye los servicios funerarios.

16 Vid. al respecto PARICIO RALLO, E., op. cit. págs. 81 y 82. 
La nueva situación que acabamos de describir tiene su reflejo en la legislación catalana aprobada tras la liberalización de los servicios funerarios en el año 1996. En Cataluña, tras la liberalización de los servicios funerarios por la ley estatal, se aprobó una ley de servicios funerarios, la ley 2/1997 de 3 de abril, en la que se reconoce esta necesaria subsistencia de la presencia ordenadora de la administración pública. Así, la exposición de motivos nos dice que "hasta la entrada en vigor del Real Decreto-ley 7/1996, de 7 de junio, sobre Medidas Urgentes de Carácter Fiscal y de Fomento y Liberalización de la Actividad Económica, los servicios funerarios han sido tradicionalmente una competencia municipal, recogida tanto en la legislación general del régimen local como en la legislación sanitaria. Lo establecido en el Real Decreto-ley 7/1996, sin embargo, implica la derogación de la reserva a favor de los entes locales de los servicios funerarios, sin perjuicio de que los Ayuntamientos puedan someter a autorización y regular la prestación de servicios por parte de los particulares en este ámbito. La posibilidad de intervención de la Administración en un sector que se declara liberalizado se explica en la medida en que éste es esencial para la comunidad y, en consecuencia, de interés general, siendo el servicio de los intereses generales el objetivo constitucional de toda la Administración pública».

Se afirma, pues, la subsistencia de un régimen de autorización y la posibilidad de regular la prestación por los particulares. El cambio esencial es el paso de un régimen de concesión al de autorización y el reconocimiento con carácter general de la prestación del servicio por los particulares. El problema, ahora, es asegurar una correcta prestación del servicio en un sistema de concurrencia, de conformidad por otro lado con la normativa comunitaria en materia de servicios y con la ley estatal de unidad de mercado ${ }^{17}$.

\section{Servicio esencial y obligaciones de servicio público}

Como hemos dicho de forma reiterada la liberalización de los servicios funerarios no supone que este servicio deje de ser esencial para los ciudadanos. La liberalización no se lleva a cabo por la pérdida del contenido de servicio esencial del servicio, sino por el hecho de que se estima que este servicio puede ser garantizado por el mercado.

Pero precisamente por este hecho, el mantenimiento del carácter de servicio esencial del servicio liberalizado, se crea la figura de los servicios económicos de interés general y se mantiene en la administración el deber de asegurar que dentro de un mercado liberalizado la prestación llegará a todos los ciudadanos ${ }^{18}$.

Por esta razón el ordenamiento otorga a la administración el poder de imponer a los prestadores privados la carga de garantizar la prestación a aquellos ciudadanos que por su situación de pobreza no pueden asumir el pago de la prestación. De este modo surge la figura de las «obligaciones de servicio público», esto es, una obligación propia del régimen de servicio público ( el acceso al mismo de todos los ciudadanos), impuesta en un régimen liberalizado, lo que ocurre cuando la actividad prestacional se califica de servicio económico de interés general, SIEG según la terminología comunitaria ${ }^{19}$.

En el caso que analizamos no hay duda de que los servicios funerarios pueden calificarse de servicios de interés general. Si volvemos a la ley catalana 2/1997 podemos recordar su Exposición de Motivos, en la que se afirma que «la posibilidad de intervención de la Administración en un sector que se declara liberalizado se explica en la medida en que éste es esencial para la comunidad y, en consecuencia, de interés general, siendo el servicio de los intereses generales el objetivo constitucional de toda la Administración pública». Consecuentemente la ley establece en su artículo primero que «los servicios funerarios tienen la condición

17 No es nuestra intención analizar en este trabajo esta importante cuestión. En todo caso destacaremos que no existe en el ordenamiento español la adaptación de la normativa sobre servicios funerarios a la Directiva $123 / 2006$. En 17 junio de 2011 se presentó por el Gobierno un Proyecto de ley que no se ha convertido en ley. De nuevo con referencia al caso catalán, la Directiva $123 / 2006$ llevó a aprobar en Cataluña el Decreto legislativo 3/2010 de 5 de octubre de adaptación de normativa catalana a la Directiva. En su artículo 11 de introdujeron una serie de modificaciones en la ley 2/1997 relativas de forma particular al régimen de autorización. La Autoridad Catalana de la Competencia emitió un Informe de Regulación relativo al proyecto de Decreto legislativo, el Informe $9 / 2010$ de 20 de mayo, en el que planteaba una serie de críticas al Proyecto al entender que no llevaba a cabo una plena trasposición de la liberalización que imponía la Directiva. Por último podemos mencionar la Guía elaborada por la Autoridad Catalana de la Competencia «para la adecuación de las ordenanzas y reglamentos municipales sobre servicios funerarios en términos de competencia», de julio 2016.

18 Este carácter de servicio económico de interés general es el que, por ejemplo, justifica la intervención del Síndic de Greuges de Cataluña en el control de la prestación del servicio por entidades privadas. Y esta es la razón que le llevó a impulsar un Codi de Bones Pràctiques de les empreses de serveis funeraris, Abril de 2016, de conformidad con la AESFC, Associació de Empreses de Serveis Funeraris de Catalunya.

19 Sobre la distinción de los conceptos de servicio público y servicio económico de interés general, vid. mi trabajo, TORNOS MAS, J., El concepto de servicio público... op. cit. 
de servicio esencial de interés general». Por tanto, la exposición de motivos reconoce la nueva realidad. El sector se ha liberalizado, ya no hay servicio público, pero es un sector de actividad económica esencial para la comunidad. Y por tanto será posible imponer a las empresas privadas y públicas que operen en el sector obligaciones de servicio público.

Esta calificación es la que lleva a la ley a establecer en su artículo 7,2.d la obligación de servicio público en los términos siguientes: "A fin de garantizar el principio de universalidad y acceso a los servicios funerarios, los Ayuntamientos pueden otorgar la autorización a las empresas que son titulares de los mismos a condición de que presten los servicios gratuitamente o de forma bonificada a las personas que, de acuerdo con las indicaciones de los servicios sociales municipales, los requieran por falta de medios económicos propios, o en los casos en que así sea acordado por la autoridad judicial. Estas prestaciones forzosas deben ser distribuidas por el Ayuntamiento entre las empresas funerarias que operan en el término municipal, de forma proporcional a la facturación de cada una de ellas» ${ }^{20}$.

La obligación, de carácter finalista ( a fin de garantizar el principio de universalidad y acceso a los servicios funerarios) se impone a las entidades autorizadas como prestaciones forzosas, sin concretar en qué puede consistir esta prestación, ya que alude tanto a la prestación gratuita como a la prestación bonificada. Con el fin de asegurar una distribución equitativa entre las empresas que compiten en el sector, se establece que la obligación de servicio público debe ser distribuida entre ellas de forma proporcional a la facturación de cada una de ellas.

La referencia a las «entidades autorizadas» como sujetos obligados a asumir la prestación forzosa no deja claro si, en el caso en que el ente local cree una empresa para prestar el servicio en ejercicio de la iniciativa pública económica, esta empresa estará también sujeta a la obligación de servicio público. Entendemos que, como la iniciativa pública económica debe llevarse a cabo en régimen de concurrencia perfecta con el sector privado, la empresa pública deberá estar sujeta a la misma obligación de servicio público ${ }^{21}$.

\section{Las competencias de ordenación en el caso de los mercados municipales}

El caso de los mercados municipales plantea otro orden de problemas. La liberalización supone en este caso que ya no debe mantenerse un mercado municipal, pero el ente local puede seguir ordenando la venta en el dominio público, de modo que de hecho puede subsistir la imagen de la existencia del mercado municipal ${ }^{22}$.

En este caso ya no nos encontramos ante un servicio público que se reconvierte en servicio económico de interés general. De hecho la actividad propia del mercado municipal la cumplen los empresarios que se dedican a la venta de los diferentes productos que se vendían antes agrupados en las diferentes paradas del mercado municipal. Por ello desaparece la razón de una intervención finalista dirigida a garantizar el

20 En este mismo sentido, el artículo 13 de la Ordenanza de servicios funerarios del Ayuntamiento de Barcelona, de 24 de octubre de 1997, establece que «Los prestadores de servicios funerarios tendrán que prever un servicio gratuito y digno para las personas sin recursos económicos debidamente justificados por certificación del Consejo Municipal del respectivo distrito. Los prestadores de servicios funerarios preverán un servicio subvencionado, que cada año fijará el Ayuntamiento de Barcelona, para aquellas personas que ingresen menos del mínimo necesario para declarar el impuesto sobre la renta de personas físicas o que cobren la pensión mínima. El número de los tipos de servicios previstos en los apartados anteriores 2 y 3 se repartirán entre todas las empresas autorizadas en proporción a la cuota de mercado de cada una de ellas. Esta cuota de mercado se calculará en función de los resultados del año inmediatamente anterior».

21 En relación con este tema el Informe de Regulación 9/2010 de 20 de mayo de la Autoridad Catalana de la Competencia formuló una observación a la regulación de la obligación de servicio público en el artículo 7 del Proyecto de ley por el que se adaptó la ley 2/1997 a la Directiva de servicios. En concreto sobre este punto dijo que «la posibilidad por parte de los Ayuntamientos de otorgar la autorización bajo la condición que el servicio se preste gratuitamente o de forma bonificada no cumple con los principios de claridad y objetividad al conceder un amplio margen de apreciación a la administración....por otro lado estas prestaciones forzosas deben poderse exigir a las empras privadas y a las públicas».

22 En este punto queremos matizar la afirmación de GONZÁLEZ BUSTOS, M. A., en su trabajo "El servicio municipal del mercado de abastos tras la ley $27 / 2013$ de racionalización y sostenibilidad de la administración local", en el libro colectivo Los servicios públicos locales. Remunicipalización y nivel óptimo de gestión, Coordinadores FONT LLOVET y DIEZ SÁNCHEZ, lustel, Madrid 2017, pág. 194. Para esta autora con la reforma legal de la LRSAL ha desaparecido la obligación de prestar el servicio de mercado municipal en municipios de más de 5.000 habitantes, afirmación que compartimos. Pero añade, que ello no supone que no pueda prestarse este servicio público en ejercicio de la competencia local propia. Como desarrollaremos más adelante a nuestro juicio la liberalización del servicio mediante la LRSAL, o mediante norma legal, no permite recrear de nuevo el servicio público por el ente local en ejercicio de sus competencias sobre el sector. El ente local puede actuar en concurrencia en ejercicio de la libre iniciativa económica, pero no volver a excluir a los privados mediante la creación de nuevo de un servicio público. 
contenido de una prestación esencial, como era el caso de los servicios funerarios, y que en el caso de los mercados no es tal.

Los títulos de intervención municipal en el caso de los mercados son otros. En este sentido cabe recordar que la normativa aplicable en materia de mercados municipales minoristas ha planteado tradicionalmente el problema de la concurrencia de las normas relativas a los servicios públicos locales, las normas en materia de bienes públicos y, con una presencia menor, las normas en materia de contratación pública.

La razón fundamental de esta concurrencia normativa es que los mercados municipales se ubican en terrenos municipales calificados como bienes demaniales de servicio público. Esto conlleva la remisión desde la normativa de bienes públicos a las normas relativas a la prestación de servicios públicos ${ }^{23}$, pero estas normativas persiguen finalidades diversas. La demanial la protección de los bienes públicos y la garantía de una explotación razonable de los mismos que no perjudique la propiedad pública. La relativa a los servicios locales tiene como finalidad garantizar una prestación de calidad, continuada y a un precio asequible para los usuarios. La de contratación, garantizar que el acceso al uso privativo se lleve a cabo según las reglas de publicidad y concurrencia para seleccionar las mejores ofertas.

La liberalización de los mercados municipales llevada a cabo conlleva que estos mercados ya no puedan mantenerse como monopolio local y que la intervención sobre los servicios que se prestan en el bien demanial donde se ubicaba el mercado municipal concebido como servicio público deberá regirse, en su caso, por la normativa de los bienes públicos. En este sentido el Informe de la Autoridad Catalana de la Competencia 49/2012 de 16 de julio sobre los mercados municipales afirma que los mismos están liberalizados y sujetos a la Directiva 123/2006. Admite que el acceso al mercado pueda sujetarse a autorización, pero demanial, y que la misma deberá respetar los principios de la Directiva, recodando a tal fin que los plazos deben ser breves, en ningún caso de 50 años $^{24}$.

\section{B) ¿Es posible remunicipalizar el servicio?}

Como hemos visto al inicio de este trabajo, en virtud de lo dispuesto en el Real Decreto ley 7/1996 y en la LRSAL, se han liberalizado los servicios públicos de servicios funerarios y mercados municipales. La consecuencia de esta liberalización es que estas actividades dejan de ser responsabilidad de la administración local y quedan abiertas a la libre iniciativa económica privada. La administración puede regular el ejercicio de estas actividades privadas, pero ya no cabe aplicar el régimen propio de los servicios públicos.

Así las cosas la segunda pregunta que queremos plantear es si los entes municipales podrían llevar a cabo la «remunicipalización» de estos servicios. Es decir, si el ente local puede decidir que en su término municipal estos servicios vuelvan a ser servicios públicos. De este modo se llevaría a cabo una verdadera remunicipalización, pues lo que se pretende es volver a asumir la prestación efectiva de una actividad como servicio público, cerrando de nuevo el mercado para estas actividades, de modo que la empresa privada sólo podría entrar mediante un título concesional ${ }^{25}$. De la competencia en el mercado se volvería, en su caso, a la competencia por el mercado si se optara por la gestión indirecta del recuperado servicio público.

Para justificar una respuesta afirmativa a nuestra pregunta ( es decir, para sostener que es posible la remunicipalización) podría acudirse al artículo 25 de la LBRL para sostener que la competencia reconocida

23 Así, por ejemplo, el artículo 54 del Reglamento de bienes de las entidades locales de Cataluña, Decreto 336/1988, establece que «el uso de los bienes de servicio público se regirá por lo dispuesto en las normas sobre servicios de los entes locales y, supletoriamente, por las de este Reglamento» (en sentido similar al artículo 87 de la ley de Patrimonio de las administraciones públicas, LPAP, $33 / 2003$ de 3 de noviembre).

24 La ordenanza municipal del Ayuntamiento de Granollers reguladora del libre acceso a las actividades de servicios y de su ejercicio en el ámbito territorial del municipio de Granollers, dictada en ejecución de la Directiva 123/2006, no sigue el criterio del Informe de la Autoridad Catalana de la Competencia. Así, establece en su artículo 2,2-b que el contenido de la Directiva no se aplica a «las actividades que impliquen el uso u ocupación del dominio público, bien por utilización privativa, bien por aprovechamiento especial, que en todo caso quedaron condicionadas a la obtención de licencia o concesión administrativa en los términos de la legislación sobre patrimonio de las administraciones públicas».

25 Decimos que se trata de una verdadera remunicipalización porque como es conocido el término remunicipalización se está utilizando de manera imprecisa jurídicamente para referirse a los procesos en virtud de los cuales la administración recupera la gestión directa de un servicio que se venía prestando de forma indirecta. Pero en estos casos el servicio nunca ha dejado de ser servicio público. Por ello el término remunicipalización es incorrecto, y debería utilizarse la expresión «reinternalización». Sobre esta cuestión vid. TORNOS MAS, J. La remunicipalización de los servicios públicos locales. Algunas precisiones conceptuales, El Cronista, lustel 58-59, 2016 
para prestar los servicios públicos que contribuyan a satisfacer las necesidades y aspiraciones de la comunidad vecinal ampara esta nueva municipalización. Se puede añadir que la modificación de los artículos 26,1 y 86,3 de la LBRL supone tan sólo que los servicios funerarios y los mercados municipales dejan de ser servicios obligatorios y reservados ex lege, pero que ello no impide su nueva configuración como servicios públicos locales ${ }^{26}$.

A nuestro entender, en principio, esta posibilidad no existe. La publicatio del servicio requiere cobertura legal. Los artículos 26 y 86,2 de la LBRL establecen la reserva, publicatio, de algunos servicios, y el artículo 86,2 añade que «el Estado y las Comunidades Autónomas, en el ámbito de sus respectivas competencias, podrán establecer, mediante ley, idéntica reserva para otras actividades y servicios».

La exigencia de reserva de ley podría excepcionarse, abriendo la posibilidad a la creación de servicios locales por el propio ente local en base al artículo 25 de la LBRL, si estos servicios se prestaran en concurrencia con el sector privado, esto es, sin monopolio. En este caso la garantía de la reserva legal podría no ser necesaria. Este podría ser el caso, por ejemplo, de la creación como servicios públicos de los gimnasios municipales, guarderías, aparcamientos o escuelas de idiomas. En estos casos estas actividades prestacionales se llevan a cabo fuera de las reglas de mercado, bajo responsabilidad municipal, en atención a su consideración de servicios de interés general. Pero estas prestaciones también se pueden llevar a cabo por entidades privadas sin necesidad de título habilitante concesional ${ }^{27}$.

No obstante, si volvemos a nuestro caso concreto, los servicios funerarios y los mercados municipales, creemos que la remunicipalización no es posible, ya que la liberalización de estos servicios se ha llevado a cabo con carácter general en todo el Estado mediante ley. El legislador ha querido suprimir un servicio público existente y abrir de forma total esta actividad económica al mercado. No cabe un contrarius actus a través de una decisión local que permitiera abrir este mercado al sector público, no en ejercicio de la iniciativa pública económica en concurrencia con las empresas privadas, lo que sí es posible, sino a través de la prestación de un servicio público con las ventajas que ello supone ( actuar fuera del mercado, con un régimen jurídico especial y con fondos públicos). Un ente local no puede hoy prestar los servicios funerarios como servicio público. Tan sólo el legislador estatal podría remunicipalizar de nuevo este servicio, y lo mismo cabe decir de los mercados municipales.

\section{C) ¿Es posible el ejercicio de la iniciativa económica pública en los sectores liberalizados?}

El ente local puede decidir ejercer la iniciativa económica en los sectores liberalizados. Donde antes intervenía como titular de la actividad, ahora podrá intervenir como un sujeto económico más, en concurrencia con las empresas privadas que actúen en este sector. Para ello deberá sujetarse a lo que establece en la actualidad el artículo 86,1 de la LBRL tras su modificación operada por la ley 27/2013, la LRSAL, y lo dispuesto a su vez en el artículo 128 de la Constitución.

26 Esta es la tesis que no compartimos y que, como ya hemos apuntado, defiende GONZÁLEZ BUSTOS, M. A., op. cit. Así se desprende de la conclusión primera de su trabajo, pág. 203: "el cambio normativo operado por la ley 27/2013 en materia de competencias locales no afecta a la posibilidad de que los municipios continúen prestando el servicio municipal de abastos, ahora considerado como un servicio dentro de una materia (artículo 25,2.i), de competencia propia, aunque se trate de un servicio no obligatorio».

27 Vid. En este sentido la sentencia del Tribunal Supremo de 6 de mayo de 1999, rec. Casación 2298/1993, en relación al caso de los aparcamientos municipales: «el motivo no puede prosperar, pues el concepto restrictivo de servicio público sobre el que gira su argumentación, coincidente con la acepción especial de servicio público esencial, esto es, de sectores de actividad reservados en principio, con o sin monopolio, a la iniciativa y gestión de la entidad pública (véase art. 128.2 CE), no se compadece con el concepto legal del artículo 85.1 de la Ley 7/1985, de 2 de abril, Reguladora de las Bases del Régimen Local, según el cual "son servicios públicos locales cuantos tienden a la consecución de los fines señalados como de la competencia de las Entidades locales", siendo de destacar la clara conexión que mantiene el servicio de aparcamiento público con la competencia sobre "la ordenación del tráfico de vehículos y personas en las vías urbanas", que el artículo 25.2 b) de la misma Ley atribuye a los Municipios; y ello sin olvidar que este mismo precepto describe con carácter general la competencia municipal incluyendo en ella la prestación de "cuantos servicios públicos contribuyan a satisfacer las necesidades y aspiraciones de la comunidad vecinal", no siendo posible desconocer que entre las necesidades actuales de la población urbana figura la de disponer de servicios de aparcamiento público. Y en cuanto a la jurisprudencia, frente a la única sentencia que cita el motivo, alusiva al concepto estricto de servicio público al que antes se ha hecho referencia, es abundante la jurisprudencia que califica específicamente como servicio público municipal la actividad de aparcamiento público prestada por particulares en régimen de concesión sobre terrenos de dominio público, pudiendo citarse en este sentido, además de la Sentencia de 27 de julio de 1983 que cita la recurrida, las de 8 de noviembre de 1990 ( RJ 199019179) y 11 de marzo y 12 de junio de 1991 (RJ $1991 / 2048$ y RJ 1991/4965), y las en ellas citadas». 
El precepto constitucional, como es conocido, estableció un sistema dual en el ejercicio de las actividades económicas, al reconocer la concurrencia de la iniciativa pública y privada sin subordinar el ejercicio de la primera al principio de subsidiariedad ${ }^{28}$.

Dentro de este marco, la iniciativa pública local podía responder a dos supuestos distintos. Por un lado, el ejercicio de la misma en régimen de libre concurrencia y, por otro, cuando se ejerce la actividad económica en sectores monopolizados, en sectores extraídos por tanto de la libre concurrencia y convertidos en servicios públicos. En estos casos la administración opta por la gestión directa pero actúa fuera del mercado ${ }^{29}$.

Pues bien, la LRSAL ha introducido en este sistema general un condicionante de especial relevancia. Como es sabido la citada ley tenía como uno de sus principales objetivos llevar al ámbito local los principios de estabilidad presupuestaria y control del déficit incorporados en la reforma del artículo 135 de la Constitución ${ }^{30}$. Consecuentemente la nueva redacción del artículo 86, en su apartado primero, establece que «las entidades locales podrán ejercer la iniciativa pública para el desarrollo de actividades económicas, siempre que esté garantizado el cumplimiento del objetivo de estabilidad y de la sostenibilidad financiera del ejercicio de sus competencias. En el expediente acreditativo de la conveniencia y oportunidad de la medida habrá de justificarse que la iniciativa no genera riesgo para la sostenibilidad financiera del conjunto de la Hacienda municipal debiendo contener un análisis del mercado, relativo a la oferta y a la demanda existente, a la rentabilidad y a los posibles efectos de la actividad local sobre la concurrencia empresarial» ${ }^{31}$.

Por tanto, en el supuesto en el que se decida llevar a cabo la iniciativa pública económica en sectores liberalizados esta libertad de opción está condicionada a la acreditación del cumplimiento del objetivo de estabilidad presupuestaria y sostenibilidad financiera. Superado este requisito, nada impide actuar en régimen de total igualdad con las empresas privadas en el ejercicio de una actividad económica de mercado. Es decir, sin gozar de ninguna de las ventajas propias que puedan derivarse de la titularidad pública de la empresa (ayudas, prerrogativas públicas...).

También deberá exigirse al ente local que justifique la razón de interés general que le lleva a ejercer la iniciativa económica en un determinado sector económico. Toda actividad administrativa, aunque sea bajo forma de actividad económica en régimen de concurrencia, debe responder a una finalidad de interés general, conforme al artículo 103 de la Constitución ${ }^{32}$.

28 En este sentido puede consultarse MARTíN RETORTILLO, S., Derecho administrativo económico, I. editorial La ley, Madrid 1988, pág. 93 y 94.

29 Esta distinción la tomamos de SOSA WAGNER, F., Manual de derecho local, Tecnos, Madrid 1986, 3. edición, págs. 177 y 178, y también de GARCÍA RUBIO, F. La iniciativa económica local tras la ley 27/2013 de 27 de diciembre de racionalización y sostenibilidad de la administración local, REALA, núm. 3, enero-junio 2015.

30 En la exposición de motivos de la LRSAL se afirma que «la reforma se plantea perseguir varios objetivos básicos, clarificar las competencias municipales para evitar duplicidades con las competencias de otras administraciones de forma que se haga efectivo el principio de una administración una competencia, racionalizar la estructura organizativa de la administración local de acuerdo con los principios de eficiencia, estabilidad y sostenibilidad financiera, garantizar un control financiero y presupuestario riguroso y favorecer la iniciativa económica privada evitando intervenciones administrativas desproporcionadas».

31 Por su parte el artículo 96 del TRRL establece que: «La iniciativa de las Entidades locales para el ejercicio de actividades económicas, cuando lo sea en régimen de libre concurrencia, podrá recaer sobre cualquier tipo de actividad que sea de utilidad pública y se preste dentro del término municipal y en beneficio de sus habitantes».

32 Vid. Al respecto GARCíA RUBIO, F., op. cit. y la sentencia Tribunal Supremo de 10 de octubre de 1989, la conocida sentencia sobre la empresa Iniciatives SA del Ayuntamiento de Barcelona, no obstante lo cual nos parece de interés recordarla de nuevo en parte: «El art. 38 de la Constitución reconoce la libertad de empresa en el marco de la economía de mercado de la que es eje básico la iniciativa privada; pero el art. 128.2 de la misma Constitución también reconoce la iniciativa pública en la actividad económica; precepto, este último, que en la esfera local ha sido desarrollado por el artículo 86.1 de su ya aludida Ley básica de 2 de abril de 1985 al establecer que las Entidades Locales, mediante expediente acreditativo de la conveniencia y oportunidad de la medida, podrán ejercer la iniciativa pública para el ejercicio de actividades económicas conforme al artículo 128.2 de la Constitución; con lo que se proclama en nuestro sistema constitucional la coexistencia de los dos sectores económicos de producción, el privado y el público, que constituyen lo que se ha dado en llamar un sistema de economía mixta; apartándose así nuestra Constitución del orden político anterior en el que primaba el principio de la subsidiariedad de la empresa pública respecto de la privada y en el que únicamente se admitía la pública ante la inexistencia o la insuficiencia de la privada, habiendo alcanzado ahora ambas el mismo rango constitucional. Y siendo esto así, no resulta acertada la tesis en la que insiste el apelante, de la supuesta ilegalidad de que el Ayuntamiento, con capital público, haya constituido una empresa privada para ejercer actividades económicas empresariales, y procede por tanto rechazarle este primer motivo de su impugnación de la sentencia recurrida.

Las anteriores afirmaciones deben sin embargo matizarse enseguida en un doble aspecto. Por un lado, mientras los particulares pueden crear sus empresas con plena libertad de criterios, sin más condición que la de que sus fines sean ilícitos (artículo 38 de la Constitución), todas las actuaciones de los Organos de la Administración Publica deben responder al interés público que en cada caso y necesariamente siempre ha de concurrir (art. 103.1 de la Constitución), tanto si se trata de actos de autoridad, como de actuaciones empresariales, pues en cuanto a estas últimas el art. 31.2 de la propia Constitución también exige una equitativa asignación de los recursos públicos y que su programación y ejecución responda a criterios de eficiencia y de economía, lo cual no es compatible con actuaciones 
REALA. Nueva Época - N. ${ }^{\circ}$, mayo 2017 - ISSN: 1989-8975 - DOI: 10.24965/reala.v0i7.10429 - [Págs. 103-114]

Liberalización de servicios públicos locales y modalidades de actuación local en los sectores liberalizados Joaquín Tornos Mas

En conclusión, en términos generales podemos concluir que la creación de una empresa municipal con el fin de llevar a cabo una iniciativa económica debe tener en cuenta los siguientes requisitos:

\section{a) De orden sustantivo}

- Garantizar el cumplimiento del objetivo de estabilidad presupuestaria y de la sostenibilidad financiera del ejercicio de sus competencias.

- Contener un análisis de mercado relativo a la oferta y a la demanda existente que garantice la rentabilidad de la empresa.

- Contener un análisis de mercado relativo a la oferta y a la demanda existente que analice los efectos de la actividad municipal sobre la concurrencia empresarial.

- Que la actividad sea de utilidad pública.

- Que la actividad se preste dentro del término municipal.

\section{b) De orden formal}

Que se tramite un procedimiento reglado y se apruebe el acuerdo de creación de la empresa por el Pleno del Ayuntamiento.

Si descendemos desde estos planteamientos generales al caso de los servicios funerarios, se pueden añadir las siguientes consideraciones.

La exigencia de razones de interés general que justifiquen la creación de una empresa municipal de servicios funerarios ha sido recordada por las sentencias del Juzgado de lo contencioso administrativo núm. 2 de Donostia de 19 de febrero de 2008, y en la del Tribunal Superior de Justicia del País Vasco, sala de lo contencioso administrativo, de 26 de abril de 2010. En la sentencia del Juzgado se recuerda que debe justificarse la razón de interés general que lleva a la creación de una empresa municipal, y que tal justificación no aparece de forma suficiente en la Memoria, y se añade que «el interés general no debe confundirse con el propio interés municipal en la intervención en el sector funerario, mediante una sociedad municipal, cuando este sector está liberalizado, y por tanto, se entiende que, en principio, es el juego de las reglas del mercado, en régimen de concurrencia competitiva el que mejor sirve a los intereses de los usuarios». En la sentencia del Tribunal Superior de Justicia, después de recordar la doctrina del Tribunal Supremo en este tema, se afirma que en el caso enjuiciado no se ha cumplido con el requisito de justificar la conveniencia y oportunidad de crear la empresa municipal, sin que frente a esta alegación se pueda sostener que en esta materia rige una amplia discrecionalidad técnica a favor del municipio, y que debe prevalecer la autonomía municipal en el momento de tomar esta decisión.

Reflexiones sin duda de especial interés, ya que obligan a justificar de forma precisa la razones que permiten excepcionar la existencia de una liberalización y las reglas del mercado ( lo que mejor sirve, se dice, a los intereses de los usuarios). Por tanto, parece imponerse un cierto principio de subsidiariedad frente a la libre decisión municipal de ejercer la iniciativa económica.

empresariales públicas carentes de justificación. Por otra parte, la coexistencia de empresas públicas con fines empresariales (artículo 128.2 de la Constitución) y de empresas privadas (artículo 38 de la misma) en el marco de una economía de mercado, y la pertenencia de España a la Comunidad Económica Europea, exigen que se garantice y salvaguarde la libre competencia, y para ello han de regir las mismas reglas para ambos sectores de producción público y privado. Por tanto, las empresas públicas que actúen en el mercado, se han de someter a las mismas cargas sociales, fiscales, financieras y de toda índole que afecten a las privadas y a sus mismos riesgos, sin poder gozar de privilegios de ningún tipo, pues ello podría impedir, restringir o falsear el juego de la libre competencia del mercado vulnerando el artículo 85 del Tratado de Roma no pudiendo tampoco estas empresas de capital público prevalecerse de ninguna forma de posición dominante ni subordinar la celebración de contratos a la aceptación por los otros contratantes de prestaciones suplementarias que por su naturaleza o según los usos mercantiles, no guarden relación alguna con el objeto de dichos contratos (art. 86 del mismo Tratado); y no pueden por último estas empresas privadas de capital público recibir ayudas ni subvenciones de fondos públicos de ninguna clase, con las solas salvedades que enumeran los apartados 2 y 3 del artículo 92 del Tratado, y aun siempre sometiendo previamente las excepciones (con una antelación mínima de 3 meses antes de poder aplicarlas) a la consideración de la Comisión del Mercado Común -artículos 93.3 del Tratado y $1 .^{\circ}, 1$ del Real Decreto 1755/1987 de 23 de diciembre-. En resumen: la creación de empresas públicas para fines empresariales es legalmente posible, pero está sujeta a la doble condición de que la actividad empresarial que se vaya a desarrollar con la empresa pública sea una actividad de indudable interés público apreciable y apreciado en el momento de su creación, y que en el ejercicio de la actividad económica empresarial de que se trate la empresa pública se someta sin excepción ni privilegio alguno directo ni indirecto a las mismas reglas de libre competencia que rigen el mercado». 
Así las cosas un posible criterio para crear una empresa municipal de servicios funerarios podría ser el tratar de introducir mayor concurrencia en un sector que a pesar de la liberalización sigue fuertemente concentrado en pocas empresas privadas. En este sentido se ha sostenido en algunos casos que el modelo actual de liberalización no funciona ya que existe un monopolio u oligopolio de facto ${ }^{33}$, por lo que la aparición de una nueva empresa municipal podría conseguir disminuir el precio medio de los servicios manteniendo la calidad ${ }^{34}$.

Pero también es cierto que este reducido nivel de competencia a nivel municipal en el conjunto de Cataluña podría corregirse con medidas de regulación del sector, sin necesidad, por tanto, de crear una empresa municipal. Así, se trataría de reducir los requisitos de entrada de nuevas empresas privadas en la actividad que se pueden considerarse injustificados, como la exigencia de poseer un tanatorio o disponer de un local social en el municipio en el que quiere actuar. También hay que destacar los factores urbanísticos conexos, como los límites para obtener suelo en el que construir un tanatorio, o la complejidad de los procedimientos de autorización para poder llevar a cabo esta actividad. En este sentido el Informe de la Autoridad Catalana de la Competencia sobre la competencia en el sector de los servicios funerarios de 2007 «recomienda que las administraciones locales sólo presten este servicio en régimen de competencia en el supuesto en que no existan empresas privadas que presten este servicio», y en el Informe de la misma Autoridad de 2016 con el título L'us del tanatori i els seus efectes sobre la competència en els serveis funeraris, se hace referencia a fomentar «la competencia mediante la construcción de nuevos tanatorios de titularidad pública ( que pueden ser gestionados por empresas privadas)». En este segundo caso debe notarse que no se propone la creación de una empresa municipal de servicios funerarios que posea un tanatorio, sino que se cree un tanatorio municipal al que puedan acceder empresas de servicios funerarios que no dispongan de tanatorio, y esta opción se propone para aquellos casos en los que no exista iniciativa privada para la construcción de tanatorios.

Por tanto, según lo que se expone en los estudios e Informes de la Autoridades de la Competencia de Cataluña el problema de la debilidad de la competencia en el sector de los servicios funerarios se debe fundamentalmente a la exigencia de disponer de un tanatorio para prestar esta actividad, a la exigencia de que el Tanatorio cuente con un elevado número de salas de velatorio, a la exigencia de contar con un local en el término municipal y a las dificultades urbanísticas para poder contar con suelo en el que poder instalar un tanatorio. Estas son las barreras de entrada.

Pues bien, estas barreras de entrada, dependen de la normativa local, por lo que antes de optar por la creación de una empresa pública en el sector de los servicios funerarios para corregir el déficit de concurrencia real, parece más conveniente utilizar el propio poder normativo local para favorecer la concurrencia de las empresas privadas. Las Autoridades de la Competencia reclaman una mayor facilidad para la entrada de empresas privadas en el sector, que son las que verdaderamente introducirán la competencia y podrán hacer realidad la voluntad liberalizadora del Real Decreto ley de 1996 y la política general de liberalización de servicios propia del derecho comunitario.

33 Así, puede afirmarse que desde la liberalización de los servicios funerarios mediante el Real Decreto ley de 1996, la competencia dentro de este sector de actividad económica en Cataluña puede calificarse, en términos generales, de débil. Así se ha puesto de manifiesto en el Informe de fiscalización de la gestión de los servicios financieros y de cementerios del Tribunal de Defensa de la Competencia, de julio de 2006, en el Estudio sobre la competencia en el sector de los servicios funerarios de la Autoridad Catalana de la Competencia, del año 2007, en las Observaciones sobre la incidencia que podrían tener determinadas medidas en el nivel de competencia de los servicios funerarios, también de la Autoridad Catalana de la Competencia, del año 2011 y en el Informe de la misma Autoridad Catalana de julio de 2016 con el título L'us del tanatori i els seus efectes sobre la competència en els serveis funeraris.

34 Este es el caso de Barcelona. En Barcelona la liberalización de los servicios funerarios comportó que en 2011 se finalizara la venta del $85 \%$ de las acciones de la sociedad municipal Serveis Funeraris de Barcelona a favor de Mémora, de modo que se crea una empresa mixta de capital mayoritariamente privado. Al mismo tiempo entra en este mercado la empresa Áltima, si bien hasta ahora con una pequeña cuota. Así las cosas el Ayuntamiento de Barcelona ha puesto en marcha el procedimiento para ejercer la iniciativa económica municipal en materia de servicios funerarios. En la Memoria justificativa, de 1 de diciembre de 2016 , se hace referencia al procedimiento a seguir y a las razones de la operación. De forma principal se alude a que el modelo liberalizado no ha funcionado en el mercado funerario, donde se dice que se ha pasado a un oligopolio privado. La creación de una empresa municipal se justifica porque la misma crearía una verdadera concurrencia y permitiría prestar el servicio a un precio más asequible sin bajar la calidad del mismo. Existe también un Plan de Viabilidad y un Informe económico. 